\title{
Cytomegalovirus myelitis in perinatally acquired HIV
}

\author{
Tayfun Güngör, Markus Funk, Richard Linde, Gert Jacobi, Markus Horn, Wolfhart Kreuz
}

\begin{abstract}
A 7 year old child perinatally infected with HIV who died from progressive muscular paralysis and central nervous respiratory failure is described. Cytomegalovirus (CMV) prophylaxis with a special intravenous CMV hyperimmunoglobulin had been successfully conducted for more than four years. Macroscopic and microscopic immunohistochemical examination of the spinal cord revealed a diffuse CMV infiltration of the entire myelon. CMV infected cells were identified as astrocytes, oligodendrocytes, neurons, macrophages, ependymal, endothelial, and Schwann cells. Other organs had no signs of CMV infection. Central nervous spinal CMV infection was most probably due to insufficient penetration of the blood-brain barrier by the CMV hyperimmunoglobulin. In suspicious cases early spinal magnetic resonance imaging ( 1.5 tesla) combined with an examination of urine and cerebrospinal fluid for $\mathrm{CMV}$ is recommended. (Arch Dis Child 1993; 68: 399-401)
\end{abstract}

Cytomegalovirus (CMV) is an important cofactor for the progression of HIV disease. ${ }^{12}$ More than $50 \%$ of all adult AIDS patients develop CMV viraemia and in $7 \%$ life threatening CMV related events are observed. Central nervous CMV infection in patients with AIDS is fairly common, and encephalitis, meningoradiculitis, myelitis, and choreoretinitis associated with HIV have been reported. ${ }^{34}$ Diagnosis of central nervous CMV infection is difficult because $\mathrm{CMV}$ isolation from cerebrospinal fluid is very seldom successful. ${ }^{5}$ Histological examination in CMV encephalitis and CMV myelitis reveals microglial nodules, cytomegalic nuclear inclusions, and sometimes focal parenchymal necrosis with vasculitis. ${ }^{5}$ Vacuolar myelopathy, most probably induced by HIV and characterised by spongious alteration of spinal white matter, is the most important differential diagnosis of CMV myelitis. ${ }^{6}$ In HIV infected children only episodes of vacuolar myelitis have been reported. ' We report a 7 year old perinatally HIV infected child who died because of CMV myelitis.

\section{Case report}

A 7 year old girl who was perinatally infected with HIV had received intravenous immunoglobulins $(7 \mathrm{~S}$-immunoglobulin in combination with a CMV hyperimmunoglobulin, $200 \mathrm{mg} / \mathrm{kg}$ body weight in exchange every two weeks) for 53 months. At 4.5 years of age the child developed neurological symptoms caused by HIV encephalopathy with ataxia, tremor, and general spasticity confirmed by computed tomography. Oral zidovudine treatment improved all symptoms and finally achieved almost full remission. By the age of 6.5 years, the child had developed spastic paraparesis followed by vertigo, Horner's syndrome, flaccid paresis of upper limbs and disturbances of micturition and defecation. Spinal and cerebral magnetic resonance imaging (MRI, 1.0 tesla) gave normal results. A second spinal scan performed by MRI ( 1.5 tesla) two weeks later revealed a cystic formation with a diffuse inflammation from C2 to C7 (fig 1). The remainder of the myelon appeared normal. At that time CMV was detectable for the first time in her urine. Serological investigations showed no signs of CMV infection or reactivation. Visual problems followed by fundoscopy revealed CMV choreoretinitis. Ganciclovir was given $(10 \mathrm{mg} / \mathrm{kg}$ body weight/day) for two weeks; this did not prevent death, which was caused by central nervous respiratory failure.

MACROSCOPIC PATHOLOGY

The cervical part of the myelon (C2-C7) was swollen. Cross sections showed pallor and reduction in consistence of the right hemimyelon as well as a cystic paracanalicular destruction of segment C7. The remaining parts of the spinal cord and roots showed no macroscopic abnormalities.

\section{MICROSCOPIC HISTOLOGICAL INVESTIGATION}

Immunocytochemistry was performed by the peroxidase-antiperoxidase method or by an avidin-biotin complex technique (streptavidinalkaline phosphatase complex) with polyclonal antibodies raised against glial fibrillary acidic protein (GFAP, Dako), S 100 protein (Dako), vimentin (Progen), factor VIII (Merck), herpes

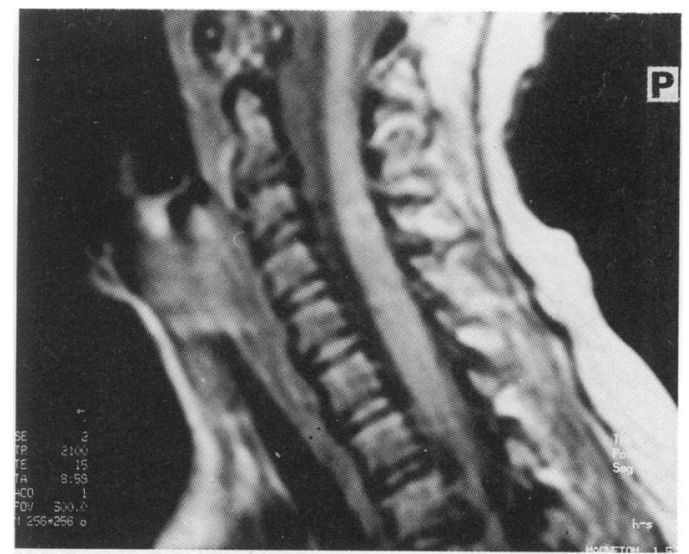

Figure 1 Cystic formation in cervical spinal cord (MRI, $1 \cdot 5$ tesla). 


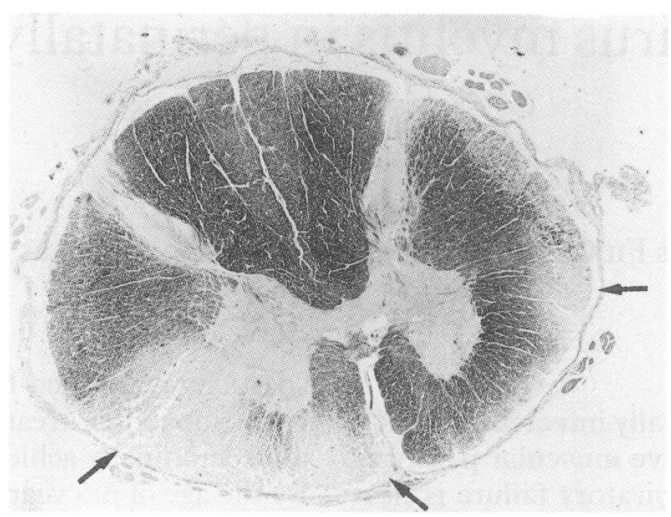

Figure 2 Necrotising myelitis in segment C3; magnification $\times 10$.

simplex virus 1 and 2 (Dako), Toxoplasma gondii (ICN) and monoclonal antibodies raised against gamma neuron specific enolase (NSE, Camon), synaptophysin antigen (Camon), clonab LN 5 (Biotest), macrophages (clone MAC 387 and EBM 11, Dako), leucocyte common antigen (LCA, Merck), CMV (Behring; Dako; clone MAB 810, Chemicon), and HIV-I glycoprotein 41 (Dupont). All sections were counterstained with haemalum. Furthermore an anti-GFAP monoclonal antibody (Boehringer Mannheim) conjugated to fluorescein (goat antimouse IgG) was applied to a series of sections that were viewed with a Zeiss fluorescence microscope.

\section{Results}

Histopathological analysis gave evidence of an extensive process of necrotising myelitis comprising approximately the entire right hemimyelon and the region of the left lateral spinothalamic tract in the segments $\mathrm{C} 2-\mathrm{C} 7$ (fig 2 ). In the thoracic segments both lateral columns and the left anterior column were involved, in the lumbar segments the white matter of both dorsal tracts, and in the sacral segments the right spinocerebellar tracts as well as the left dorsolateral white matter. All lesions contained numerous mononucleated or multinucleated cells that showed characteristic basophilic nuclear inclusions located within necrotic areas $\mathrm{r}$ within some spots of nodular gliosis. They corresponded to cytomegalic or so called owl eye cells. The spinal roots showed no histological signs of inflammation or disintegration.

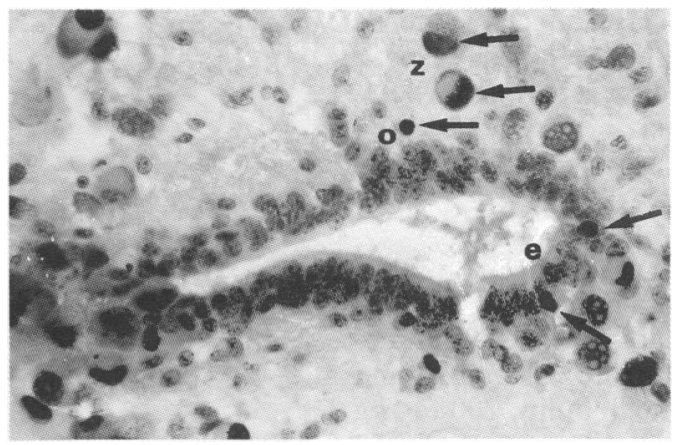

Figure 3 Immunohistochemical staining of CMV infection in different cells of segment $C 5:$ ependymal cells of the central
canal $(e)$, oligodendrocytes $(o)$, and characteristic owl eye cells $(\boldsymbol{z})$; magnification $\times 200$.
Nearly all cytomegalic cells, most astrocytes, oligodendrocytes, macrophages, a small number of neurons, some ependymal and endothelial cells, and singular Schwann cells of cervical roots were labelled by immunostaining with antiCMV antibodies (fig 3). Testing of antibodies against herpes simplex virus type 1 and 2, HIV-I glycoprotein 41 , and $T$ gondii gave completely negative results. The majority of cytomegalic cells showed strong reaction with antibodies to GFAP and a few were immunostained by antibodies to vimentin, panmacrophage antigen, and factor VIII. None of the cytomegalic cells stained with leucocyte common antigen.

The other internal organs had no signs of CMV infection. The neuropathological examination was restricted to the spinal cord and roots because the parents had not given permission for removal of the brain.

\section{Discussion}

In adult AIDS patients with CMV specific neurohistology, necrotising encephalitis (57\%) and nodular encephalitis ( $43 \%$ ) could be differentiated. ${ }^{8}$ With the aid of immunocytochemistry different authors reported that they were able to detect HIV induced myelopathy with microglial nodes in $20-30 \%$ and $C M V$ induced myelopathy in $10-20 \%$ at necropsy in adult patients with AIDS. ${ }^{59}$ Simultaneous spinal infection with both viruses has also been described. ${ }^{9}$ Applying in situ hybridisation more cases of nodular encephalopathy and myelitis seem to be caused by CMV than previously considered. This is reflected in a Swiss study in 206 of adult AIDS patients that demonstrated a rate of $20 \%$ of nodular encephalitis, while ordinary immunohistochemical CMV specific techniques were positive in only $7 \% .^{10}$ Our case report demonstrates that $\mathrm{CMV}$ myelitis is an opportunistic infection that should be kept in mind by a paediatrician caring for HIV infected children. This perinatally infected child who had been classified as having full blown AIDS for 27 months developed a focal necrotising myelitis in cervical, thoracic, lumbar, and sacral myelon. Conventional histology and immunocytochemistry identified CMV cells as astrocytes, oligodendrocytes, neurons, macrophages, endothelial, ependymal, and Schwann cells. A double infection with CMV and HIV could not be shown." The majority of CMV cells were astrocytes, the minority macrophages, mesenchymal, and endothelial cells. ${ }^{12}$

The fact that there was no CMV manifestation of other internal organs indicated that intravenous CMV prophylaxis might have been able to prevent systemic CMV infection. Its lacking penetration of the blood-brain barrier might have been responsible for isolated central nervous system CMV infection. Children with symptoms as described above should be investigated by MRI ( 1.5 tesla) for spinal inflammation. CMV excretion in urine might be one of the first positive laboratory hints for active CMV infection. CMV detection in cerebrospinal fluid should always be attempted even though it is often unsatisfactory. New techniques like the polymerase chain reaction are encouraging new diagnostic tools that might be helpful in early 
CMV detection. ${ }^{13}$ The question of whether antiviral treatment with ganciclovir or foscarnet ${ }^{14}$ is able to treat effectively central nervous CMV infection in paediatric AIDS patients needs further investigation.

1 Casareale D, Fiala M, Chang CM, Cone LA, Mocarski ES Cytomegalovirus enhances lysis of HIV-infected Cytomegalovirus enhances lysis of

2 Webster A, Lee CA, Cook DG, et al. Cytomegalovirus infection and progression towards AIDS in haemophiliacs infection and progression towards AIDS in haemophiliacs with hum

3 Mahieux F, Gray F, Fenelon G, et al. Acute myeloradiculitis due to cytomegalovirus as the initial manifestation of AIDS. f Neurol Neurosurg Psychiatry 1989; 52: 270-4.

4 Morgello S, Cho ES, Nielsen S, et al. Cytomegalovirus encephalitis in patients with acquired immunodeficiency syndrome. An autopsy study of 30 cases and a review of the literature. Hum Pathol 1987; 18: 289-97.

5 Grafe MR, Wiley CA. Spinal cord and peripheral nerve pathology in AIDS: the roles of cytomegalovirus human immunodeficiency virus. Ann Neurol 1989; 25: 561-6.

6 Artigas J, Grosse G, Niedobitek P. Vacuolar myelopathy in AIDS. A morphological analysis. Pathol Res Pract 1990; 186: $228-37$.

7 Dickson DW, Belman AL, Kim TS, Horoupian DS, Rubinstein A. Spinal cord pathology in pediatric acquired immunodeficiency syndrome. Neurology $1989 ; 39$ (2 Pt 1): immunodef.
8 Schmidbauer M, Budka H, Ulrich W, et al. Cytomegalovirus (CMV) disease of the brain in AIDS and connatal infection a comparative study by histology, immunocytochemistry and in situ DNA hybridization. Acta Neuropathol (Berl) 1989; 79: 286-93.

9 Vinters HV, Kwok MK, Ho HW, et al. Cytomegalovirus in the nervous system of patients with the acquired immunodeficiency syndrome. Brain 1989; 112 (Pt 1): 245-68.

10 Lang W, Probst A, Miklossy J, et al. Nervous system pathology in AIDS: results of a collaborative autopsy study from Switzerland. Schweiz Rundsch Med Prax 1990; 79. 562-8.

11 Bélec L, Gray F, Mikol J, Scaravilli F, Mhiri C, Sobel A, Poirier J. Cytomegalovirus (CMV) encephalomyeoradiculitis and human immunodeficiency virus (HIV encephalitis: presence of HIV and CMV co-infected multinucleated giant cells. Acta Neuropathol (Berl) 1990; 81: 99 104 .

12 Horn $M$, Schlote W, Herrmann G, Güngör T, Jacobi G mmunocytochemical characterization of cytomegaloviru (CMV) infected giant cells in perinatal acquired human immunodeficiency virus (HIV) infection. Acta Histochem (fena) 1992; suppl XLII: 115-22.

13 Cassol SA, Poon MCh, Pal R, et al. Primer-mediated enzymatic amplification of cytomegalovirus (CMV) DNA application to the early diagnosis of CMV infection in marrow transplant recipients. $\mathcal{f}$ Clin Invest $1989 ; 83.1109$ 15 .

14 Studies of ocular complications of AIDS research group in collaboration with the AIDS Clinical Trials Group. Mortality in with the AIDS Clinical Trials Group. cyndrom in patients with the acquired immuno deficiency cyndrome treated with eicher foscarn 